\title{
Correction to: Stopping Denosumab
}

\section{Olivier Lamy ${ }^{1,2}$ - Delphine Stoll ${ }^{1}$ • Bérengère Aubry-Rozier ${ }^{1,3}$ • Elena Gonzalez Rodriguez ${ }^{1,4}$}

Published online: 31 January 2021

(C) Springer Science+Business Media, LLC, part of Springer Nature 2020

\section{Correction to: Current Osteoporosis Reports (2019) 17(1):8-15 https://doi.org/10.1007/s11914-019-00502-4}

The author Elena Gonzalez Rodriguez is not properly referenced in PubMed. The reference shows as "Rodriguez E.G.", but should be "Gonzalez Rodriguez E.".

Publisher's Note Springer Nature remains neutral with regard to jurisdictional claims in published maps and institutional affiliations.

The online version of the original article can be found at https://doi.org/ 10.1007/s11914-019-00502-4

Olivier Lamy

Olivier.lamy@chuv.ch

1 Center of Bone Diseases, Lausanne University Hospital,

Lausanne, Switzerland

2 Service of Internal Medicine, CHUV, Lausanne University Hospital, Rue du Bugnon 46, CH-1011 Lausanne, Switzerland

3 Service of Rheumatology, Lausanne University Hospital, Lausanne, Switzerland

4 Service of Endocrinology, Diabetes and Metabolism, Lausanne University Hospital, Lausanne, Switzerland 